\title{
Elevated serum levels of macrophage-derived chemokine and thymus and activation-regulated chemokine in autistic children
}

\author{
Laila Yousef AL-Ayadhi ${ }^{1}$ and Gehan Ahmed Mostafa ${ }^{1,2^{*}}$
}

\begin{abstract}
Background: In some autistic children, there is an imbalance of T helper (Th)1/Th2 lymphocytes toward Th2, which may be responsible for the induction of the production of autoantibodies in these children. Th2 lymphocytes express CCR4 receptors. CCR4 ligands include macrophage-derived chemokine (MDC) and thymus and activation-regulated chemokine (TARC). They direct trafficking and recruitment of Th2 cells. We are the first to measure serum levels of CCR4 ligands in relation to the degree of the severity of autism.

Methods: Serum concentrations of MDC and TARC were measured, by quantitative sandwich enzyme immunoassay technique, in 56 autistic children and 32 healthy matched children.

Results: Autistic children had significantly higher serum levels of MDC and TARC than healthy controls $(P<0.001$ and $P<0.001$, respectively). Children with severe autism had significantly higher serum levels of MDC and TARC than patients with mild to moderate autism $(P<0.001$ and $P=0.01$, respectively). In addition, there were significant positive correlations between CARS and serum levels of both MDC $(P<0.001)$ and TARC $(P<0.001)$ in children with autism. There were significant positive correlations between serum levels of MDC and TARC in autistic children $(P<0.001)$.

Conclusions: Serum levels of CCR4 ligands were elevated in autistic children and they were significantly correlated to the degree of the severity of autism. However, further research is warranted to determine the pathogenic role of CCR4 ligands in autism and to shed light on the therapeutic role of CCR4-ligand antagonism in autistic children.
\end{abstract}

Keywords: Autism, Autoimmunity, Childhood Autism Rating Scale, CCR4 ligands, Macrophage-derived chemokine, Thymus and activation-regulated chemokine

\section{Background}

Recruitment of inflammatory cells plays the key pathogenic role in all inflammatory and autoimmune diseases. Inflammation is characterized by the local tissue expression of chemokines, a large group of chemotactic cytokines, which play an important pathogenic role in inflammatory diseases by enhancement of leukocyte recruitment and activation at inflammatory sites [1-4].

CCR4 is a receptor that binds two $8 \mathrm{kDa} \mathrm{CC}$ chemokines, macrophage-derived chemokine (MDC/

\footnotetext{
* Correspondence: hafezg@softhome.net

'Autism Research and Treatment Center, AL-Amodi Autism Research Chair, Department of Physiology, Faculty of Medicine, King Saud University, Riyadh, Saudi Arabia

${ }^{2}$ Department of Pediatrics, Faculty of Medicine, Ain Shams University, 9

Ahmed El-Samman Street off Makram Ebaid, Nasr City, Cairo 11511, Egypt
}

CCL22) and thymus and activation-regulated chemokine (TARC/CCL17) [5]. MDC is synthesized by cells of macrophage lineage, while TARC is expressed in the thymus. The gene encoding both chemokines is clustered on chromosome 16q13 [6-8]. CCR4 ligands, MDC and TARC, act on their CCR4 receptors to enhance the recruitment and activation of $\mathrm{T}$ helper (Th) 2 cells with a subsequent production of type 2 cytokines that include interleukin-4 (IL-4), IL-5, IL-9 and IL-13 [9,10]. The Th2associated chemokines, MDC and TARC, were the highest at birth and then decreased with age [11]. CCR4 ligands have an important pathogenic role in inflammatory conditions such as allergy and some autoimmune diseases [12-18]. Chemokines and their receptors have been 
implicated as functional mediators of immunopathology of autoimmune neuroinflammatory diseases [19,20].

The presence of autoantibodies to neural tissues/antigens in autism [21-28] and the increase in the frequency of autoimmune disorders among autistic families [29-33] suggest that autoimmunity may play an important role in the pathogenesis of autism [21].

This study aimed to measure serum levels of CCR4 ligands in relation to the degree of the severity of autism in a group of autistic children.

\section{Methods}

\section{Study population}

This cross-sectional study was conducted on 56 autistic children. They were recruited from the Autism Research and Treatment Center, Faculty of Medicine, King Saud University, Riyadh, Saudi Arabia. Patients fulfilled the criteria of the diagnosis of autism according to the 4th edition of the Diagnostic and Statistical Manual of Mental Disorders [34]. The autistic group comprised 46 males and 10 females. Their ages ranged between 4 and 12 years (mean $\pm \mathrm{SD}=7.54 \pm 1.96$ years). Patients who had associated neurological diseases (such as cerebral palsy and tuberous sclerosis), metabolic disorders (for example phenylketonuria), allergic manifestations or concomitant infection were excluded from the study.

The control group comprised 32 age- and sexmatched apparently healthy children. They included 26 males and 6 females. They were the healthy older siblings of the healthy infants who attend the Well Baby Clinic, King Khalid University Hospital, Faculty of Medicine, King Saud University, Riyadh, Saudi Arabia for the routine following up of their growth parameters. The control children were not related to the children with autism, and demonstrated no clinical findings suggestive of infections, allergic manifestations and immunological or neuropsychiatric disorders. Their ages ranged between 5 and 11 years (mean $\pm \mathrm{SD}=7.19 \pm 1.69$ years). The local Ethical Committee of the Faculty of Medicine, King Saud University, Riyadh, Saudi Arabia, approved this study. In addition, an informed written consent of participation in the study was signed by the parents or the legal guardians of the studied subjects.

\section{Study measurements}

\section{Clinical evaluation of autistic patients}

This was based on clinical history taking from caregivers, clinical examination and neuropsychiatric assessment. In addition, the degree of the disease severity was assessed by using the Childhood Autism Rating Scale (CARS) [35] which rates the child on a scale from one to four in each of fifteen areas (relating to people; emotional response; imitation; body use; object use; listening response; fear or nervousness; verbal communication; nonverbal communication; activity level; level and consistency of intellectual response; adaptation to change; visual response; taste, smell and touch response and general impressions). According to the scale, children who have scored 30 to 36 have mild to moderate autism $(\mathrm{n}=20)$, while those with scores ranging between 37 and 60 points have a severe degree of autism $(\mathrm{n}=36)$.

\section{Serum assessment of MDC and TARC levels}

The assay employed the quantitative sandwich enzyme immunoassay technique using the Quantikin Human MDC/CCL22 and TARC-CCL17 immunoassay kits (both kits were supplied from R\&D Systems Inc., Minneapolis, MN, USA). A monoclonal antibody specific for MDC or TARC had been precoated onto a microplate. Standards and samples were pipetted into the wells and any MDC or TARC present was bound by the immobilized antibody. After washing away any unbound antibody-enzyme reagent, a substrate solution was added to the wells and color developed in proportion to the amount of MDC or TARC bound in the initial step. The color development was stopped and the intensity of the color was measured $[7,16]$. To increase accuracy, all samples were analyzed twice in two independent experiments to assess the interassay variations and to ensure reproducibility of the observed results. There were no discordant data between the results $(P>0.05)$. No significant cross-reactivity or interference was observed.

\section{Statistical analysis}

The results were analyzed by using the commercially available software package (Statview, Abacus Concepts, Inc., Berkley, CA, USA). The data were nonparametric, thus they were presented as median and interquartile range (IQR), which are between the 25th and 75th percentiles. The Mann-Whitney test was used for comparison between these data. A chi-square test was used for comparison between qualitative variables of the studied groups. Spearman's rho correlation coefficient ' $r$ ' was used to determine the relationship between different variables. For all tests, a probability $(P)$ of less than 0.05 was considered significant.

\section{Results}

Autistic children had significantly higher serum levels of MDC $($ median $(\mathrm{IQR})=1289.5(1079) \mathrm{pg} / \mathrm{ml})$ than healthy controls $($ median $(\mathrm{IQR})=190(295) \mathrm{pg} / \mathrm{ml}), \quad P<0.001$ (Figure 1). Similarly, autistic children had significantly higher serum levels of TARC (median (IQR) $=880.5$ (1206) $\mathrm{pg} / \mathrm{ml}$ ) than healthy children (median $(\mathrm{IQR})=$ 137.25 (173) $\mathrm{pg} / \mathrm{ml}$ ), $P<0.001$, (Figure 2).

Children with severe autism had significantly higher serum levels of MDC and TARC than patients with mild 


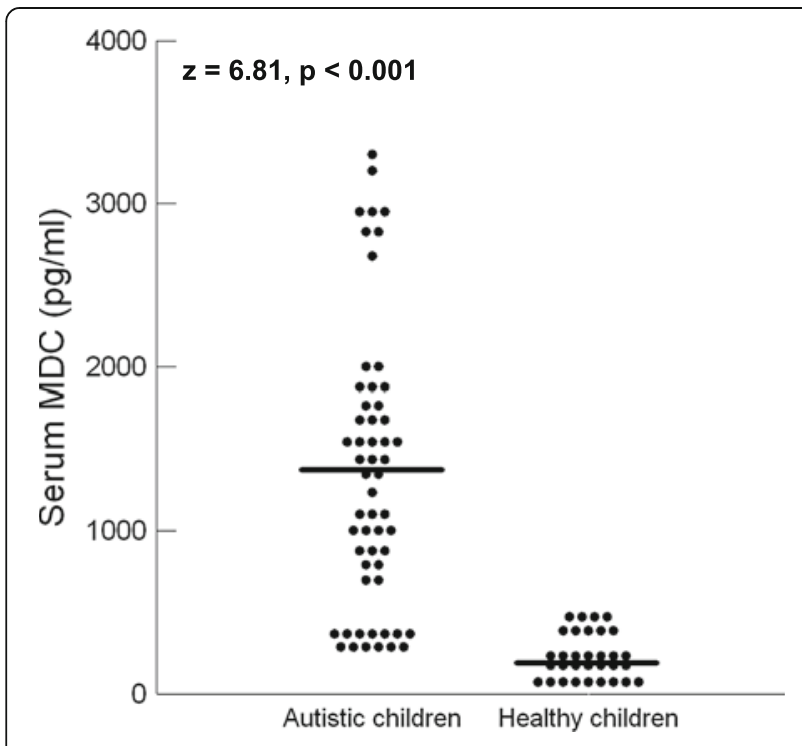

Figure 1 Serum levels of MDC in autistic patients and healthy controls. MDC, macrophage-derived chemokine. Horizontal bars indicate the median values.

to moderate autism $(\mathrm{P}<0.001$ and $\mathrm{P}=0.01$, respectively), Table 1. In addition, there were significant positive correlations between CARS and serum levels of both MDC $(\mathrm{r}=0.93, \mathrm{P}<0.001)$ and TARC $(\mathrm{r}=0.87, \mathrm{P}<0.001)$ in children with autism.

There were significant positive correlations between serum levels of MDC and TARC in autistic children, $\mathrm{P}<0.001$ (Figure 3).

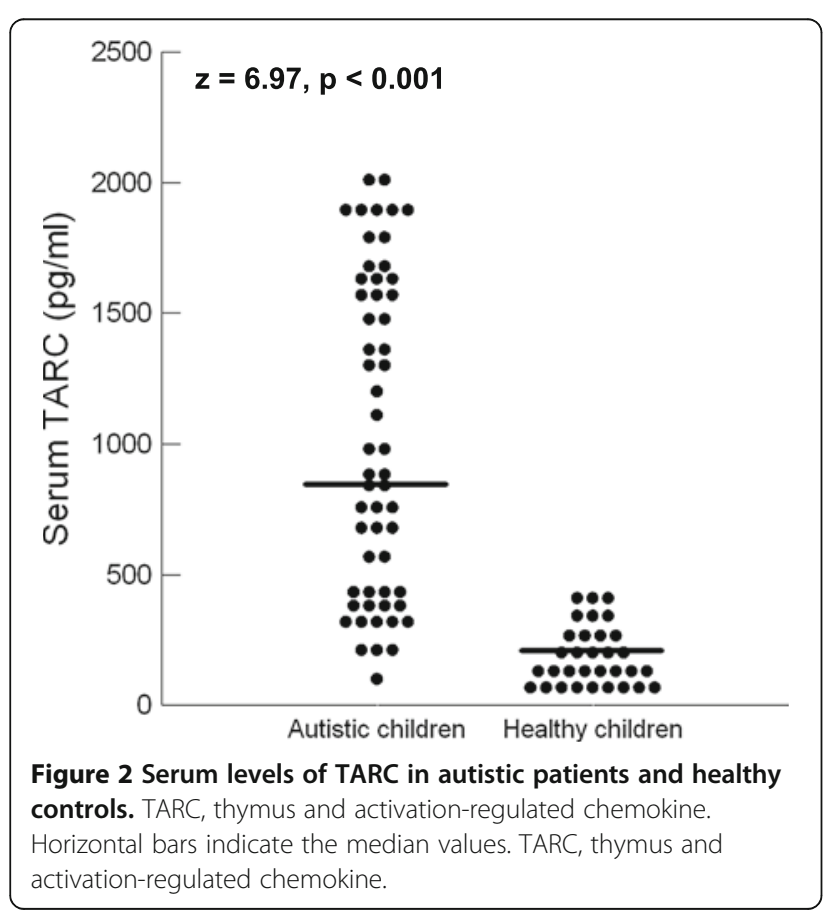

Serum levels of both MDC and TARC had no significant correlations with the age of the children with autism $(P=0.87$ and $P=0.47)$, respectively. In addition, there was no significant difference between male and female autistic children in serum levels of both MDC $(P>0.05)$ and TARC $(P>0.05)$.

All study subjects had normal weight (body mass index (BMI) was between the 5th and less than the 85th percentiles based on age and sex). There was no significant difference between the BMI of healthy children and autistic children $(P>0.05)$. In addition, there were no significant correlations between the BMI and serum levels of both MDC $(P>0.05)$ and TARC $(P>0.05)$ in children with autism.

\section{Discussion}

CCR4 ligands direct trafficking and recruitment of Th2 cells $[9,10]$ and they were reported to play an important role in some autoimmune diseases [15-18]. In the present study, autistic children had significantly higher serum levels of MDC and TARC than healthy controls $(P<0.001$ and $P<0.001$, respectively). A previous study reported increased MDC and TARC in the anterior cingulate gyrus of autistic patients [36]. Proinflammatory chemokines, such as TARC and monocyte chemotactic protein-1 (MCP-1) along with proinflammatory cytokines were reported to be elevated in the brains of some individuals with autism.

The transport or synthesis of cytokines in the brain may contribute to neuroinflammation and possible neurotransmitter imbalances in autism [21]. Abnormal immune responses, as assessed by multiplex analysis of cytokines and chemokines, may serve as one of the biological trait markers for autism [37]. Active neuroinflammatory process in the cerebral cortex, white matter, and notably in cerebellum of autistic patients was reported. Immunocytochemical studies showed marked activation of microglia and astroglia, and cytokine profiling indicated that macrophage chemoattractant protein-1 and tumor growth factor-beta1, derived from neuroglia, were the most prevalent cytokines in brain tissues. Cerebrospinal fluid (CSF) showed a unique proinflammatory profile of cytokines, including a marked increase in MCP-1 [36].

Elevated levels of chemokines have been detected in the brain and CSF of individuals with autism. Few studies have examined chemokine levels in the plasma of children with autism, but these studies did not correlate the plasma levels of chemokines with the disease severity. Elevated plasma MCP-1, RANTES and eotaxin in some autistic children and their association with more impaired behaviors may have etiological significance. Chemokines and their receptors might provide unique targets for future therapies in autism [38]. Another study reported decreased plasma levels of chemokines involved 
Table 1 Serum levels of MDC and TARC in relation to the severity of autism

\begin{tabular}{lccc}
\hline $\begin{array}{l}\text { Serum CCR4 } \\
\text { ligands }\end{array}$ & $\begin{array}{c}\text { Patients with mild to moderate autism }(\mathbf{n}=\mathbf{2 0}) \\
\text { Median }(\text { IQR) }\end{array}$ & $\begin{array}{c}\text { Patients with severe autism }(\mathbf{n}=\mathbf{3 6}) \\
\text { Median (IQR) }\end{array}$ & $\mathbf{Z}(\mathbf{P}$-value) \\
\hline Serum MDC $(\mathrm{pg} / \mathrm{ml})$ & $767.5(649)$ & $634(451)$ & $4.8(<0.001)$ \\
Serum TARC $(\mathrm{pg} / \mathrm{ml})$ & $1623(651)$ & $1469(1217)$ & $3.2(0.01)$ \\
\hline
\end{tabular}

MDC Macrophage-derived chemokine, TARC thymus and activation-regulated chemokine.

in hematopoiesis and the Th cell immune system in the children with autism compared with unrelated siblings without autism. The investigators of this study recommended further studies to confirm immunological disturbances influencing hematopoiesis and antibody production in the children with autism [39]. An increased risk for infantile autism with elevated MCP-1 in amniotic fluid was recently reported. Elevated levels of MCP-1 may play an indirect role in the pathophysiology of autism [40].

This study is the first to investigate serum levels of CCR4 ligands in relation to the degree of the severity of autism, which was assessed by using CARS. In the present work, children with severe autism had significantly higher serum levels of MDC than patients with mild to moderate autism $(P<0.001$ and $P=0.01$, respectively). There were significant positive correlations between the values of CARS and serum levels of both MDC $(P<0.001)$ and TARC $(P<0.001)$ in autistic children. This may indicate that the extent of the elevation of CCR4 ligands was closely linked to the degree of the severity of autism. However, it is not easy to determine whether this increase is a mere consequence of autism or has a pathogenic role in the disease. Further research is warranted to determine the pathogenic role of CCR4 ligands and their relation to serum levels of brain-specific autoantibodies in autistic children.

CCR4 ligands have many cellular sources including monocyte-derived dendritic cells, keratinocytes and bronchial epithelial cells [41-43]. MDC is also produced by natural killer cells and macrophages [44]. Early signals elicited during innate immune response, such as Th2-type cytokines and bacterial products, induce the rapid secretion of CCR4 $[45,46]$. The current study revealed significant positive correlations between serum MDC and serum TARC levels in autistic children $(P<0.001)$. This could be explained by the fact that MDC is produced concomitantly with TARC during immune inflammation. Both chemokines are ligands to the same receptor, which is characterized on Th2 cells [9] resulting in the activation and long-term recruitment of Th2 cells [47] and subsequently in the pathomechanism of some autoimmune diseases, including autism [15-17].

Both Th2 chemoattractants, MDC and TARC, were reported to be elevated and play a role in some autoimmune diseases such as systemic lupus erythematosus

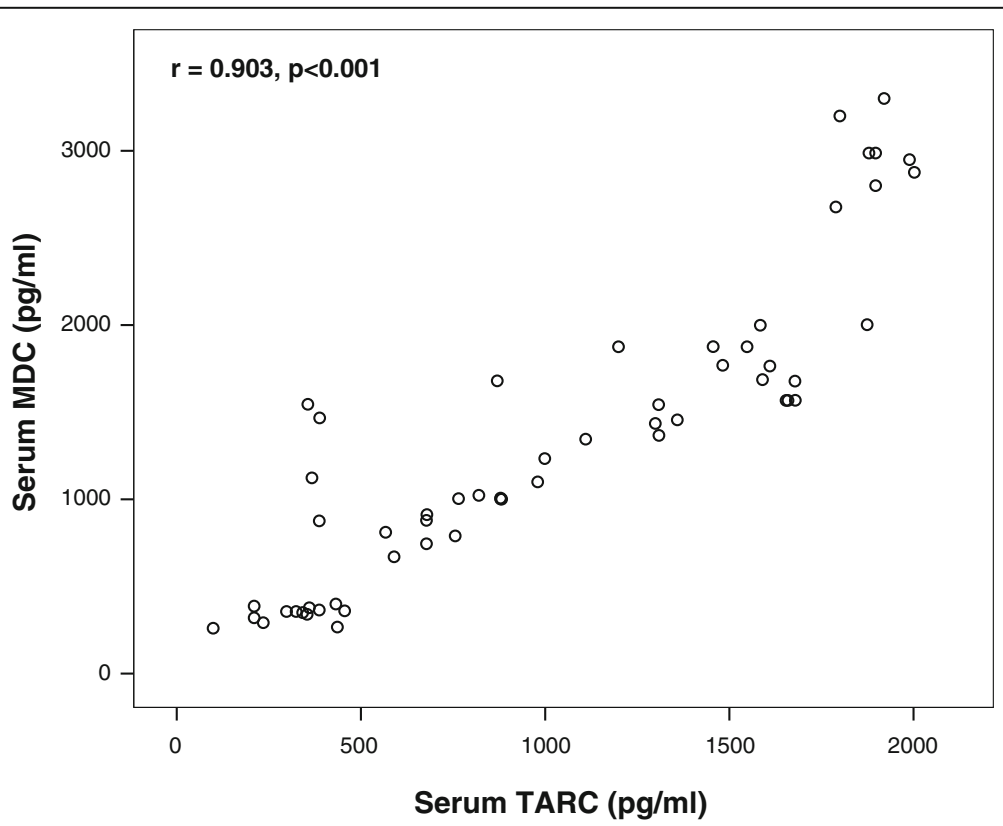

Figure 3 Positive correlations between serum levels of MDC and TARC in autistic patients. MDC, macrophage-derived chemokine, TARC, thymus and activation- regulated chemokine. 
[15] and systemic sclerosis [16]. In addition, MDC levels were reported to be elevated in the CSF of female patients with multiple sclerosis (MS). MDC was suggested to play a role in the development of MS possibly by influencing the intracerebral recruitment of Th2 cells which express CCR4 receptors [17]. Furthermore, MDC plays a role in experimental autoimmune encephalomyelitis (EAE), the animal model of MS. MDC/CCL22 gene is a part of a chemokine cluster, which includes also TARC/CCL17. The frequency of the $\mathrm{C} / \mathrm{T}$ and $\mathrm{C} / \mathrm{A}$ single nucleotide polymorphisms (SNPs) in the promoter and coding sequence of CCL22 as well as the C/T SNP in the promoter of CCL17 were determined in 370 patients with MS compared with 380 controls. A trend toward a decreased allelic frequency of the A allele of the CCL22 C/A SNP as well as of the T allele of the CCL17 C/T SNP was found in patients compared with controls [19]. Similar genetic studies of MDC/ CCL22 gene are recommended in children with autism.

The immunomodulatory effects of CCR 4 ligands may act not only through modulation of Th cell function, but also through decreasing the induction of CD4 + CD25high regulatory $\mathrm{T}$ cells (T-regs) and the promotion of the differentiation of Th17 cells [48]. Th17 cells have been implicated in the pathogenesis of autoimmune diseases, which is supported by recent clinical trials using anti-IL-17 in the treatment of these diseases. Th17 cells are characterized by a strong IL-17-producing capacity. IL-17 family cytokines control the inflammatory responses by triggering the secretion of proinflammatory cytokines and chemokines [49,50]. In addition, T-regs play an important role in the establishment of the immunological selftolerance and thereby, prevent autoimmunity as T-regs suppress Th17 cells [51]. One study reported deficiency of T-regs in $73.3 \%$ of autistic children [32]. Another studies reported significantly higher plasma concentrations of IL-17 [37,52] and some of Th2 cytokines, such as IL-5 and IL-13, in autistic children compared to healthy matched controls $[37,38]$.

Previous studies reported the possible pathogenic role of Th2 cells, Th17 cells and deficiency of T-regs in the induction of autoimmunity in a subgroup of patients with autism $[32,35,36,50]$. The results of this study may indicate the possible contributing role of CCR4 ligands in the induction of autoimmunity in autism, possibly as a result of long-term recruitment of Th2 cells, suppression of the induction of T-regs and enhancement of the differentiation of Th17 cells. However, this is an initial report that cannot prove the pathogenic role of CCR4 ligands in autism, but rather raises additional questions. So, these data should be treated with caution until further investigations are performed. Studies should be conducted to investigate the relationship between serum levels of CCR4 ligands and both T-regs and Th17 cells in children with autism.
Decreasing chemokine receptor binding may be an important potential therapeutic target in allergy and immunology [4]. This can be performed by using small molecule chemokine receptors antagonists or by using blocking antibodies [53]. Thus, studies concerning the effect of CCR4-ligand antagonism on amelioration of autistic manifestations in children are mandatory.

\section{Conclusions}

Serum levels of CCR4 ligands were elevated in autistic children and they were significantly correlated to the degree of the severity of autism. However, further research is warranted to determine the pathogenic role of CCR4 ligands in autism and to shed light on the therapeutic role of CCR4-ligand antagonism in autistic children.

\section{Abbreviations}

BMl: Body mass index; CARS: Childhood Autism Rating Scale;

EAE: Experimental autoimmune encephalomyelitis; IL: Interleukin; IQR: Interquartile range; MDC: Macrophage-derived chemokine; MCP-

1: Monocyte chemotactic protein-1; SNPs: Single Nucleotide Polymorphisms; TARC: Thymus and activation- regulated chemokine; Th: T-helper; MS: Multiple sclerosis; Tregs: CD4 + CD25 high regulatory T-cells.

\section{Competing interests}

The authors declare that they have no competing interests.

\section{Authors' contributions}

Both authors designed, performed and wrote the research. In addition, both authors read and approved the final manuscript.

\section{Acknowledgements}

This work was financially supported by the King Abdulaziz City for Science and Technology, Riyadh, Saudi Arabia. It was also supported by NPST, Health Research and Studies program at Kind Saud University.

Received: 12 March 2013 Accepted: 21 May 2013

Published: 19 June 2013

\section{References}

1. Ono SJ, Nakamura T, Miyazaki D, Ohbayashi M, Dawson M, Toda M: Chemokines: roles in leukocyte development, trafficking and effector function. J Allergy Clin Immunol 2003, 111:1185-1199.

2. Sanz MJ, Kubes P: Neutrophil-active chemokines in in vivo imaging of neutrophil trafficking. Eur J Immunol 2012, 42:278-283.

3. Lira SA, Furtado GC: The biology of chemokines and their receptors. Immunol Res 2012, 54:111-120.

4. Smith JJ, Lukacs NW: A closer look at chemokines and their role in asthmatic responses. Eur J Pharmacol 2006, 3:277-288.

5. Vestergaard C, Deleuran M, Gesser B, Gronhoj LC: Expression of the T-helper 2-specific chemokine receptor CCR4 on CCR10-positive lymphocytes in atopic dermatitis skin but not in psoriasis skin. Br J Dermatol 2003, 149:457-463.

6. Kakinuma T, Nakamura K, Wakugawa M, Mitsui H, Tada Y, Saeki H, Torii H, Komine M, Asahina A, Tamaki K: Serum macrophage derived chemokine (MDC) levels are closely related with the disease activity of atopic dermatitis. Clin Exp Immunol 2002, 12:270-273.

7. Mantovani A, Gray PA, van Damme J, Sozzani S: Macrophage-derived chemokine (MDC). J Leukoc Biol 2000, 68:400-404.

8. Imai T, Baba M, Nishimura M, Kakizaki M, Takagi S, Yoshie O: The T cell-directed CC chemokine TARC is a highly specific biological ligand for CC chemokine receptor 4. J Biol Chem 1997, 272:15036-15042.

9. Kunkel EJ, Boisvert J, Murphy K, Vierra MA, Genovese MC, Wardlaw AJ, Greenberg HB, Hodge MR, Wu L, Butcher EC, Campbell JJ: Expression of the chemokine receptors CCR4, CCR5, and CXCR3 by human tissue infiltrating lymphocytes. Am J Pathol 2002, 160:347-355. 
10. Bhowmick S, Chatterjee D, Chaudhuri K: Human epithelial cells stimulated with Vibrio cholerae produce thymic stromal lymphopoietin and promote dendritic cell-mediated inflammatory Th2 response. Int J Biochem Cell Biol 2012, 44:1779-1790.

11. Abrahamsson TR, Sandberg Abelius M, Forsberg A, Björkstén B, Jenmalm MC: A Th1/Th2-associated chemokine imbalance during infancy in children developing eczema, wheeze and sensitization. Clin Exp Allergy 2011, 41:1729-1739.

12. Oliphant CJ, Barlow $J \mathrm{~L}$, McKenzie AN: Insights into the initiation of type 2 immune responses. Immunology 2011, 134:378-385.

13. Machura E, Rusek-Zychma M, Jachimowicz M, Wrzask M, Mazur B, Kasperska-Zajac A: Serum TARC and CTACK concentrations in children with atopic dermatitis, allergic asthma, and urticaria. Pediatr Allergy Immunol 2012, 23:278-284.

14. Abelius MS, Ernerudh J, Berg G, Matthiesen L, Nilsson LJ, Jenmalm MC: High cord blood levels of the T-helper 2-associated chemokines CCL17 and CCL22 precede allergy development during the first 6 years of life. Pediatr Res 2011, 70:495-500.

15. Okamoto H, Koizumi K, Yamanaka H, Saito T, Kamatani N: A role for TARC/CCL17, a CC chemokine, in systemic lupus erythematosus. J Rheumatol 2003, 30:2369-2373.

16. Fujii $H$, Shimada $Y$, Hasegawa $M$, Takehara $K$, Sato S: Serum levels of a Th1 chemoattractant IP-10 and Th2 chemoattractants, TARC and MDC, are elevated in patients with systemic sclerosis. J Dermato/ Sci 2004 35:43-51.

17. Galimberti D, Fenoglio C, Comi C, Scalabrini D, De Riz M, Leone M, Venturelli E, Cortini F, Piola M, Monaco F, Bresolin N, Scarpini E: MDC/CCL22 intrathecal levels in patients with multiple sclerosis. Mult Scler 2008, 14:547-549.

18. Galimberti D, Scalabrini D, Fenoglio C, De Riz M, Comi C, Venturelli E, Cortini F, Piola M, Leone M, Dianzani U, D'Alfonso S, Monaco F, Bresolin N, Scarpini E: Gender-specific influence of the chromosome 16 chemokine gene cluster on the susceptibility to multiple sclerosis. J Neurol Sci 2008, 267:86-90.

19. Karpus WJ, Fife BT, Kennedy KJ: Immunoneutralization of chemokines for the prevention and treatment of central nervous system autoimmune disease. Methods 2003, 29:362-368.

20. Karpus WJ, Ransohoff RM: Chemokine regulation of experimental autoimmune encephalomyelitis: temporal and spatial expression patterns govern disease pathogenesis. J Immunol 1998, 161:2667-2671.

21. Cohly HH, Panja A: Immunological findings in autism. Int Rev Neurobiol 2005, 71:317-341.

22. Singh VK, Warren RP, Averett R, Ghaziuddin M: Circulating autoantibodies to neuronal and glial filament proteins in autism. Pediatr Neurol 1997, 17:88-90.

23. Mostafa GA, El-Sayed ZA, Abd El Aziz MM, El-Sayed MF: Serum anti-myelin -associated glycoprotein antibodies in Egyptian autistic children. J Child Neurol 2008, 23:1413-1418.

24. Mostafa GA, Al-Ayadhi LY: Increased serum levels of anti-ganglioside M1 auto-antibodies in autistic children: relation to the disease severity. J Neuroinflammation 2011, 8:39.

25. Mostafa GA, Al-Ayadhi LY: A lack of association between hyperserotonemia and the increased frequency of serum anti-myelin basic protein auto-antibodies in autistic children. J Neuroinflammation 2011, 8:71

26. Mostafa GA, Al-Ayadhi LY: The possible link between the elevated serum levels of neurokinin $A$ and anti-ribosomal $P$ protein antibodies in children with autism. J Neuroinflammation 2011, 8:180

27. Al-Ayadhi LY, Mostafa GA: A lack of association between elevated serum levels of $\mathrm{S100B}$ protein and autoimmunity in autistic children. J Neuroinflammation 2012, 9:54

28. Mostafa GA, Al-Ayadhi LY: The relationship between the increased frequency of serum antineuronal antibodies and the severity of autism in children. Eur J Paediatr Neurol 2012, 16:464-468.

29. Sweeten TL, Bowyer SL, Posey DJ, Halberstadt GM, McDougle CJ: Increased prevalence of familial autoimmunity in probands with pervasive developmental disorders. Pediatrics 2003, 112:420-424.

30. Mostafa GA, Kitchener N: Serum anti-nuclear antibodies as a marker of autoimmunity in Egyptian autistic children. Pediatr Neurol 2009, 40:107-112.
31. Mostafa GA, Shehab A: The link of C4B null allele to autism and to a family history of autoimmunity in Egyptian autistic children. J Neuroimmunol 2010, 223:115-119.

32. Mostafa GA, Al Shehab A, Fouad NR: Increased frequency of CD4 + CD25high regulatoryT cells in the peripheral blood of Egyptian children with autism. J Child Neurol 2010, 25:328-335.

33. Mostafa GA, El-Hadidi ES, Hewedi DH, Abdou MM: Oxidative stress in Egyptian children with autism: relation to autoimmunity. J Neuroimmunol 2010, 219:114-118

34. American Psychiatric Association: Diagnostic and statistical manual of mental disorders. 4th edition. Washington DC: American Psychiatric Association; 1994.

35. Schopler E, Reichler RJ, Renner BR: The childhood autism rating scale (CARS), for diagnostic screening and classification in autism. New York. NY: Irvington; 1986.

36. Vargas DL, Nascimbene C, Krishnan C, Zimmerman AW, Pardo CA: Neuroglial activation and neuroinflammation in the brain of patients with autism. Ann Neurol 2005, 57:67-81.

37. Suzuki K, Matsuzaki H, Iwata K, Kameno Y, Shimmura C, Kawai S, Yoshihara Y, Wakuda T, Takebayashi K, Takagai S, Matsumoto K, Tsuchiya KJ, Iwata Y, Nakamura K, Tsujii M, Sugiyama T, Mori N: Plasma cytokine profiles in subjects with high-functioning autism spectrum disorders. PLoS One 2011, 6:e20470.

38. Ashwood P, Krakowiak P, Hertz-Picciotto I, Hansen R, Pessah IN, Van de Water JJ: Associations of impaired behaviors with elevated plasma chemokines in autism spectrum disorders. Neuroimmunol 2011, 232:196-199.

39. Manzardo AM, Henkhaus R, Dhillon S, Butler MG: Plasma cytokine levels in children with autistic disorder and unrelated siblings. Int I Dev Neurosci 2012, 30:121-127.

40. Abdallah MW, Larsen N, Grove J, Nørgaard-Pedersen B, Thorsen P, Mortensen EL, Hougaard DM: Amniotic fluid chemokines and autism spectrum disorders: an exploratory study utilizing a Danish historic birth cohort. Brain Behav Immun 2012, 26:170-176.

41. Hirata H, Arima M, Cheng G, Honda K, Fukushima F, Yoshida N, Eda F, Fukuda T: Production of TARC and MDC by naive T cells in asthmatic patients. J Clin Immunol 2003, 23:34-45.

42. Zlotnik A, Yoshie O: Chemokines: a new classification system and their role in immunity. Immunity 2000, 12:121-127.

43. Reiss Y, Proudfoot AE, Power CA, Campbell JJ, Butcher EC: CC chemokine receptor (CCR) 4 and the CCR10 ligand cutaneous T cell-attracting chemokine (CTACK) in lymphocyte trafficking to inflamed skin. J Exp Med 2001, 194:1541-1547.

44. Pinho V, Oliveira SH, Souza DG, Vasconcelos D, Alessandri AL, Lukacs NW, Teixeira MM: The role of CCL22 (MDC) for the recruitment of eosinophils during allergic pleurisy in mice. J Leukoc Biol 2003, 73:356-362.

45. Minshall EM, Cameron L, Lavigne F, Leung DY, Hamilos D, Garcia-Zepada EA, Rothenberg M, Luster AD, Hamid Q: Eotaxin mRNA and protein expression in chronic sinusitis and allergen induced nasal responses in seasonal allergic rhinitis. Am J Respir Cell Mol Biol 1997, 17:683-690.

46. Proost $P$, Wuyts $A$, Van Damme J: Human monocyte chemotactic proteins-2 and -3: structural and functional comparison with MCP-1. J Leukoc Biol 1996, 59:67-74.

47. Sebastiani S, Danelon G, Gerber B, Uguccioni M: CCL22-induced responses are powerfully enhanced by synergy inducing chemokines via CCR4. evidence for the involvement of first beta-strand of chemokine. Eur $J$ Immunol 2005, 35:746-756.

48. Heiseke AF, Faul AC, Lehr HA, Förster I, Schmid RM, Krug AB, Reindl W: CCL17 promotes intestinal inflammation in mice and counteracts regulatory T cell-mediated protection from colitis. Gastroenterology 2012 142:335-345.

49. Jadidi-Niaragh F, Mirshafiey A: Th17 Cell, the new player of neuroinflammatory process in multiple sclerosis. Scand J Immunol 2011, 74:1-13

50. Hueber W, Patel DD, Dryja T, Wright AM, Koroleva I, Bruin G, Antoni C, Draelos Z, Gold MH, Psoriasis Study Group, Durez P, Tak PP, Gomez-Reino J, Rheumatoid Arthritis Study Group, Foster CS, Kim RY, Samson CM, Falk NS, Chu DS, Callanan D, Nguyen QD, Uveitis Study Group, Rose K, Haider A, Di Padova F: Effects of AIN457, a fully human antibody to interleukin-17A, on psoriasis, rheumatoid arthritis, and uveitis. Sci Trans/ Med 2010, 2:52-72. 
51. Vignali DA, Collison LW, Workman CJ: How regulatory T cells work. Nat Rev Immunol 2008, 8:523-532.

52. Al-Ayadhi LY, Mostafa GA: Elevated serum levels of interleukin-17A in children with autism. J Neuroinflammation 2012, 9:158,

53. Alam R, Busse WW: The eosinophil-quo vadis? J Allergy Clin Immunol 2004, 113:8-42.

doi:10.1186/1742-2094-10-72

Cite this article as: AL-Ayadhi and Mostafa: Elevated serum levels of macrophage-derived chemokine and thymus and activation-regulated chemokine in autistic children. Journal of Neuroinflammation 2013 10:72.

\section{Submit your next manuscript to BioMed Central and take full advantage of:}

- Convenient online submission

- Thorough peer review

- No space constraints or color figure charges

- Immediate publication on acceptance

- Inclusion in PubMed, CAS, Scopus and Google Scholar

- Research which is freely available for redistribution 